are divided into rounded and irregular and classified as to size in three grades $(\mathrm{p}, \mathrm{q}, \mathrm{r}$ and $\mathrm{s}, \mathrm{t}, \mathrm{u}$ respectively). The frequency of these opacities is on a 12-point scale, the first figure being the standard film category considered nearest to the film being classified and the figure after the oblique being the nearest alternative standard film. Thus, if the observer classifies a film as category 2 but would consider as the nearest alternative classification category 1 , then the grading is $2 / 1$. This means that category $Z$ in the short version would be classified as $0 / 1$ or $1 / 0$ in the extended, according to whether the observer felt the 0 or the 1 standard film approximated more closely to the appearance seen. When the observer is in no doubt and considers the changes the same as one of the standards, he uses the grade number twice, viz. $1 / 1$ or $2 / 2$. In this extended scheme there is detailed grading of changes in the pleura and pericardium which have been developed with particular reference to those produced by asbestos exposure. The separation of isolated 'costophrenic angle' (cpa) pleural thickening from the other categories is due to its greater prevalence and lack of correlation with dust exposure.

The booklet gives lucid instructions as to how the classification should be used and also the best techniques for obtaining suitable radiographs. It mentions briefly the history of the development and testing of this and preceding classifications but makes scant reference to the long, tedious hours which many devoted workers have put in front of $x$-ray viewing boxes, in long-distance air transport, and around committee tables to make this classification work.

Tables 2 and 3 are reproduced from the International Classification of Radiographs of Pneumoconioses with the permission of the International Labour Office.

\section{Reference}

International Classification of Radiographs of Pneumoconioses. Occupational Health Series, No. 22, 1970, I.L.O. Occupational Health and Safety Branch, CH 1211, Geneva 22. Free of charge. 24 pp., 3 tables.

\title{
Gas chromatographic determination of phosgene and dichloroacetylene in air $^{1}$
}

\author{
R. JELTES, E. BURGHARDT, and J. BREMAN \\ Research Institute for Public Health Engineering TNO, P.O. Box 214, Delft, Netherlands
}

Jeltes, R., Burghardt, E., and Breman, J. (1971). Brit. J. industr. Med., 28, 96-99. Gas chromatographic determination of phosgene and dichloroacetylene in air. Phosgene and dichloroacetylene vapours may be present in the working environment near places where chlorinated hydrocarbons are used, including exposure chambers and the like in which people or animals are deliberately exposed to chlorinated hydrocarbons to investigate the effects of these substances. A gas liquid chromatographic method was developed for the determination of sub-Threshold Limit Value concentrations of phosgene and dichloroacetylene. Using electron capture detection, concentrations from $0.02 \mathrm{ppm}$ of each compound could be determined.

1Publication no. 357 of the Research Institute for Public Health Engineering TNO. 
Chlorinated hydrocarbons are used in large quantities in industry. These substances may decompose under certain conditions and give rise to the formation of, among other substances, the very toxic compounds phosgene and dichloroacetylene (Smith, 1966; Farhi, Morel, and Cavigneaux, 1968), each having a Threshold Limit Value (1968) of $0 \cdot 1 \mathrm{ppm}$. Phosgene as such is also used in chemical industry. Because these two compounds may contaminate air, a method for their determination was needed. A convenient method would also be important in investigations in which people or animals are exposed to chlorinated hydrocarbons to test their effects.

Phosgene hydrolyses quickly and smells like newmown hay. The odour can be detected by some people at $0.5 \mathrm{ppm}$ or less (Priestley, Critchfield, Ketcham, and Cavender, 1965). Dichloroacetylene is toxic and explosive.

A search of the literature revealed no analytical methods for the determination of dichloroacetylene in air. For phosgene there were no satisfactory methods for low concentrations before 1961 (Saltzman, 1961). Crummett and McLean (1965) published an ultraviolet absorption method, based on the formation of $\mathbf{N}, \mathrm{N}^{\prime}$-diphenylurea from the reaction of phosgene with aniline. The phosgene was collected in aqueous solution, and the method was quantitative down to $0.01 \mathrm{ppm}$ in air samples of 30 litres or more. Linch, Lord, Kubitz, and De Brunner (1965) used the 'Model-480-phosgene-inair-Analyzer' from Du Pont for continuous colorimetric determination. With 4,4'-bis-(diethylamino)benzophenone specific and sensitive determinations $(0 \cdot 1$ to $10 \mathrm{ppm})$ were possible. In 'Methods for the Detection of Toxic Substances in Air' (Ministry of Labour, 1967) is a semi-quantitative method for 0.05 to $0.4 \mathrm{ppm}$ using indicator paper impregnated with 4-(4'-nitrobenzyl)pyridine and $\mathrm{N}$-benzylaniline. The colour obtained is compared with standards. In addition, various types of indicator tubes, packed with a carrier material impregnated with reagents, have been described. When air is drawn through them, they give a colour change which is related to the phosgene concentration (Linch et al., 1965; Spěvák and Kratochvíl, 1965; Dräger, 1968). With Dräger tubes it is possible to detect $0.05 \mathrm{ppm}$. In some of these methods, filters of sodium iodide and sodium thiosulphate are used to prevent interference by chlorine and hydrogen chloride (Spěvák and Kratochvíl, 1965; Ministry of Labour, 1967).

With these methods, low concentrations of phosgene in air can be measured with tolerable specificity. However, gas liquid chromatography (GLC) with electron capture detection (ECD) seemed to us more useful, as with it very sensitive and specific estimations could be made of other organic chlorine compounds in the same sample. This is not so by any of the other methods.
Gas chromatography with ECD has been used by Stewart, Swank, Roberts, and Dodd (1963) for 0.002 to $0.010 \mathrm{ppm}$ of trichloroethylene in the air expired by human beings. The sensitivity is related to the number of halogen atoms per molecule. For trichloroethylene Boettner and Dallos (1965) gave it as $8.5 \times 10^{-3} \mu \mathrm{g}$ for the less specific, flame ionization detector and $0.02 \times 10^{-3} \mu \mathrm{g}$ for the ECD. According to Linch et al. (1965), gas chromatography with ECD is not useful for traces of phosgene in air. Priestley and his colleagues(1965), however, published such a method for 0.001 to $2 \mathrm{ppm}$ of phosgene alone in air. For calibration, a dynamic triple dilution system was used, and air samples were analysed directly on the gas chromatograph. The column consisted of $2 \mathrm{~m} \times 4.7 \mathrm{~mm}$ internal diameter aluminium packed with $30 \%$ didecyl phthalate on 100 to 120 mesh GC-22 Super Support.

We have investigated a similar method, with which one can determine low concentrations of both phosgene and dichloroacetylene simultaneously in one sample and without interference from substances such as trichloroethylene from which they may be formed.

\section{Experimental}

Chemicals

Phosgene was obtained from Fluka (a $20 \%$ by weight solution in toluene). Dichloroacetylene, prepared for us by another TNO-institute, was obtained as a solution of $0.1 \%$ by weight in toluene.

\section{Gas chromatographic conditions}

An Aerograph Model 1520 GLC apparatus equipped with a tritium electron capture detector was used. The potential applied to the detector was $90 \mathrm{~V}$. The apparatus was fitted with a $2.5 \mathrm{~m} \times 1.5 \mathrm{~mm}$ internal diameter aluminium column, packed with $30 \%$ diisodecyl phthalate (Hewlett-Packard) coated on 80 to 100 mesh Aeropak (Varian-Aerograph). The injection port and detector oven were operated at $35^{\circ}$ and $150^{\circ} \mathrm{C}$ respectively. The column was operated isothermally at $50^{\circ} \mathrm{C}$. The nitrogen flow was controlled at $30 \mathrm{ml} /$ minute.

Samples of the air under investigation were introduced directly into the column by means of a gas-tight syringe (Hamilton).

To remove traces of oxygen, which is detected by ECD, from the carrier gas, use was made of a filter tube packed with BASF (Ludwigshafen, West Germany) catalyst $\mathbf{R}$ 3-11.

\section{Calibration}

For calibration test concentrations of $0.1 \mathrm{ppm}$, of phosgene and dichloroacetylene in air were prepared as follows. A 2-litre Erlenmeyer flask was conditioned with some millitres of toluene solutions of $0.1 \mathrm{~g} /$ litre of phosgene and $0.1 \%$ dichloroacetylene and afterwards flushed with air. This was necessary to saturate the walls with the compounds. The flask was closed with a rubber stopper enveloped in Teflon tape and provided with a septum-containing attachment through which samples 
could be obtained by means of a gas-tight syringe. The calculated quantity of a dilute solution of phosgene and dichloroacetylene was injected into the flask and left to evaporate. Mixing was assured with a magnetic stirrer.

For concentrations lower than $0.1 \mathrm{ppm}$ a gas-tight syringe was partially filled with the test air, which was then further diluted in the syringe with air. The concentrations so prepared were analysed, and a calibration curve was constructed.

Air samples containing these low concentrations were compared with a few samples with similar quantities of phosgene and dichloroacetylene in solution.

Because of the risk of rapid hydrolysis of phosgene, dry conditions are of the utmost importance. Hexane was preferred to toluene for dilution of the concentrated phosgene solution. Stable low concentrations of phosgene in toluene could not be prepared, whereas in hexane low concentrations remained constant for hours. All glassware used was dried at $100^{\circ} \mathrm{C}$. Syringes for liquids were cleaned with hexane before use, and not with a polar liquid like acetone. For phosgene and dichloroacetylene in the gas phase, we used air dried with Anhydrone (anhydrous magnesium perchlorate).

\section{Results}

The Figure shows that separation of phosgene and dichloroacetylene was possible. The retention times were respectively 1 minute 54 seconds and 3 minutes
33 seconds. Trichloroethylene, from which the other two components might have originated, eluted only after 22 minutes 8 seconds. The one unknown peak in the Figure was of a contaminant in the air used. No other components being present, one determination could be made every 4 minutes.

Equal small quantities in air and in liquid solvents gave very similar recordings.

The phosgene concentrations in the test gas remained constant for at least an hour, the dichloroacetylene concentrations for 6 hours.

From chromatograms obtained, it could be concluded that $\mathbf{0 . 0 2} \mathrm{ppm}$ could just be determined (Figure). Sometimes, however, depending on the momentary detector sensitivity, $\mathbf{0 . 0 0 5} \mathrm{ppm}$ or lower could be detected. The Table shows the results from calibration. $0 \cdot 1 \mathrm{ppm}$ concentrations of phosgene (1) and dichloroacetylene (2) in air in three repeated analyses gave the following peak heights (cm): 5.00 (1) and 2.52 (2); 4.95 (1) and 2.51 (2); and 5.00 (1) and $2 \cdot 52$ (2). Reproducibility was dependent on the use of good, leak-tight gas syringes.

\section{Discussion}

With ECD concentrations of phosgene and dichloroacetylene in air lower than the threshold limit value

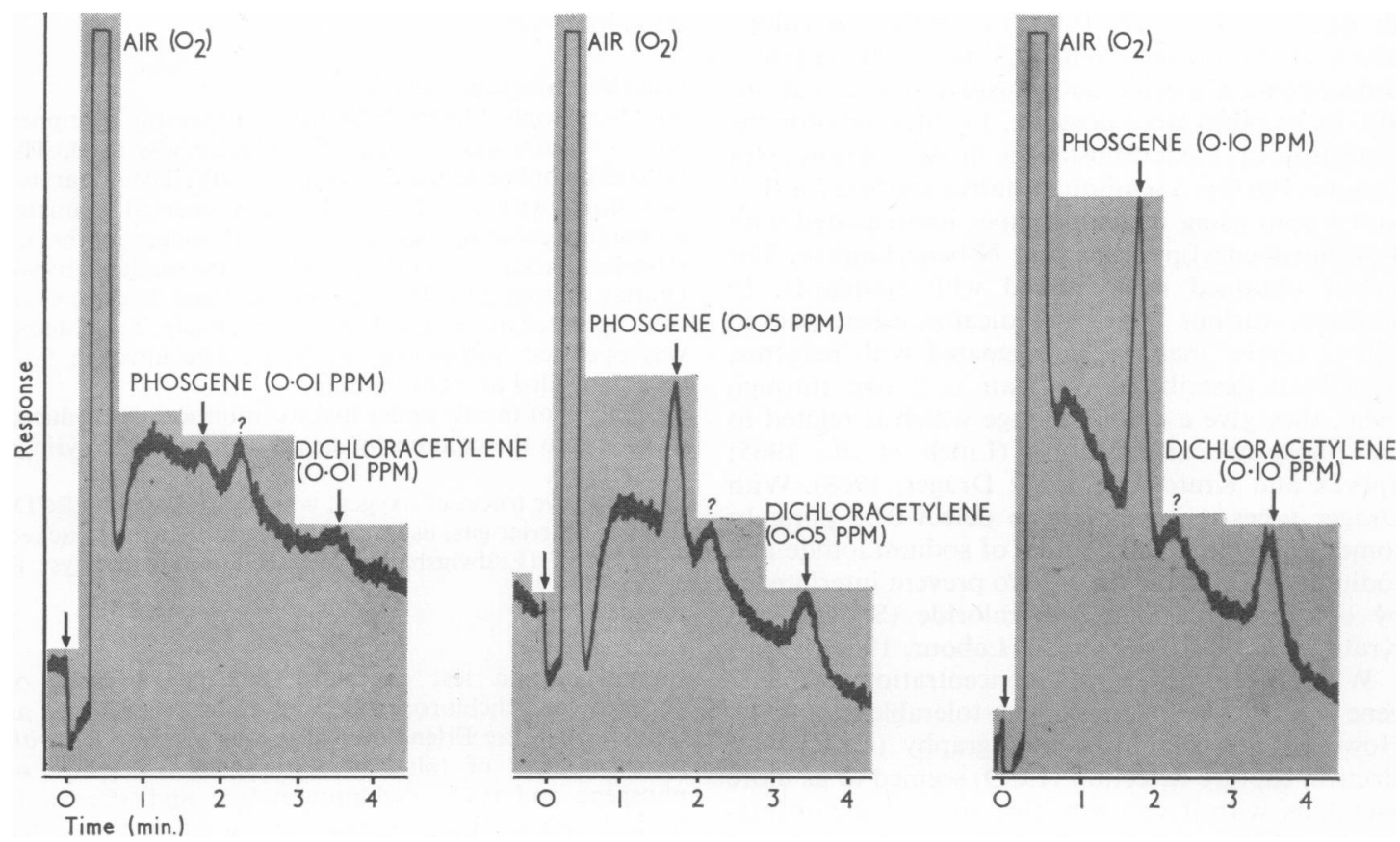

FIGURE Gas chromatograms of traces of phosgene and dichloroacetylene in air. Sample size $0.5 \mathrm{ml}$. Electrometer range 1 , attenuator 1 . 
concentrations can be determined. In our method phosgene eluted fast, owing to the small diameter of our column. Small column diameters give better separations but have the disadvantage that the phosgene and dichloroacetylene peaks are positioned on the slope at the back of the air peak (Figure).

Because of interferences possible with ECD, we deem it necessary to calibrate during each series of measurements.

ECD is very sensitive to some compounds, mostly with high boiling points, but it is likely that a peak from a low-boiling component is caused by a halogenated hydrocarbon. In spite of certain disadvantages, ECD is often the best choice, because there is no other detector with the same sensitivity or specificity.

If phosgene and dichloroacetylene occur together with another, usually higher-boiling, chlorinated hydrocarbon, the analysis time may be increased. Air samples, however, can be analysed continually as long as no higher component elutes, so that when, for example, trichloroethylene is also present, which under our conditions has an elution time width of 5 minutes, the number of analyses which can be carried out per hour is only reduced from 15 to 12. High concentrations of halogenated hydrocarbons may impair the functioning of the ECD. To counter this, smaller samples may be applied, or a three-way valve may be introduced at the output end of the column so that the unwanted compounds can be flushed into the air or into a flame ionization detector.

The ECD did not respond linearly to the concentrations of phosgene and dichloroacetylene (Table). For dichloroacetylene this is probably because ECD systems respond linearly over only a small range. For phosgene it is probably due to decomposition, for instance by water, or by absorption on the solid support.

In the calibration experiments much inconvenience was caused by traces of water. Dry materials and conditions had to be used. During calibration there was a chance of wall-adsorption. To investigate this, some air samples were compared with samples containing equal quantities of phosgene and dichloroacetylene in solution. Because there were no differences in the results, we conclude that in the gas phase there is no more adsorption than in the liquid phase.

The syringes used may be a source of error. To obtain good results their leak-tightness has to be checked very frequently.
TABLE

Calibration of Phosgene and DichloROACETYLENE CONCENTRATIONS

\begin{tabular}{c|cc}
\hline \multirow{2}{*}{$\begin{array}{c}\text { Concentration } \\
(\text { ppm })\end{array}$} & \multicolumn{2}{|c}{${\text { Peak } \text { area }^{1}\left(\mathrm{~cm}^{2}\right)}$} \\
\cline { 2 - 3 } & Phosgene & Dichloroacetylene \\
\hline 0.01 & 0.08 & 0.185 \\
0.02 & 0.22 & 0.24 \\
0.05 & 0.74 & 0.475 \\
0.10 & 1.8 & 0.86 \\
& & \\
\hline
\end{tabular}

The sample size was $0.5 \mathrm{ml}$

${ }^{1}$ Electrometer settings: range 1 , attenuation 1

Because of the instability of the compounds, it is best to have the gas chromatographic system in the working area; but it is possible to transfer air samples in a syringe to an adjacent area. It is not practicable to store air samples for more than a very short time.

\section{References}

Boettner, E. A., and Dallos, F. C. (1965). Analysis of air and breath for chlorinated hydrocarbons by infrared and gas chromatographic techniques. Amer. industr. Hyg. Ass. J., 26, 289-293.

Crummett, W. B., and McLean, J. D. (1965). Ultraviolet spectrophotometric determination of trace quantities of phosgene in gases. Analyt. Chem. (Wash.), 37, 424-425.

Dräger (1968). Dräger Tube Phosgene 0.05/a. Drägerwerk Lübeck, 1st ed. 234-194e.

Farhi, M., Morel, Mme, and Cavigneaux, A. (1968). Phosgène. Cahiers de Notes Documentaires, pp. 397-400.

Hygienic Guide Series (1968). Phosgene. Amer. industr. Hyg. Ass. J., 29, 308-311.

Linch, A. L., Lord, S. S. Jr., Kubitz, K. A., and De Brunner, M. R. (1965). Phosgene in air-development of improved detection procedures. Amer. industr. Hyg. Ass. J., 26, 465-474.

Ministry of Labour (1967). Methods for the detection of toxic substances in air. Booklet No. 8. Phosgene, 3rd ed., H.M. Factory Inspectorate, London.

Priestley, L. J. Jr., Critchfield, F. E., Ketcham, N. H., and Cavender, J.D. (1965). Determination of subtoxic concentrations of phosgene in air by electron capture gas chromatography. Analyt. Chem. (Wash.), 37, 70-71.

Saltzman, B. E. (1961). Preparation and analysis of calibrated low concentrations of sixteen toxic gases. Analyt. Chem. (Wash.), 33, 1100-1112.

Smith, G. F. (1966). Trichlorethylene: A review. Brit. J. industr. Med., 23, 249-262.

Spěvák, A., and Kratochvíl, V. (1965). Rapid semi-quantitative determination of phosgene concentration in the air. Chem. Prümysl, 15, 682-685 (in Czech, English summary).

Stewart, R. D., Swank, J. D., Roberts, C. B., and Dodd, H. C. (1963). Detection of halogenated hydrocarbons in the expired air of human beings using the electron capture detection. Nature (Lond.), 198, 696-697.

Threshold Limit Values of airborne contaminants for 1968 (1968). American Conference of Governmental Industrial Hygienists, Cincinnati, U.S.A.

Received for publication March 31, 1970 